\section{Awareness and uptake of the Pap smear among market women in Lagos, Nigeria}

\author{
Kikelomo O. Wright, ${ }^{1}$ Babalola Faseru, ${ }^{2}$ \\ Yetunde A. Kuyinu, ${ }^{1}$ Francis A. Faduyile ${ }^{3}$ \\ 'Department of Community Health \\ and Primary Health Care, Lagos State \\ University College of Medicine, Lagos, \\ Nigeria; ${ }^{2}$ Department of Preventive \\ Medicine and Public Health, University \\ of Kansas Medical Center and School \\ of Medicine, Kansas City, Kansas, USA; \\ ${ }^{3}$ Department of Pathology and Forensic \\ Medicine, Lagos State University College \\ of Medicine, Lagos, Nigeria
}

\section{Abstract}

Our study evaluates the effect of an educational programme on awareness and uptake of the cervical cancer screening test (Pap smear) by women in a model market in Lagos, Nigeria. This was a quasi-experimental study using a multistage sampling technique. A total of 350 women were divided into two groups. A baseline survey on awareness of the Pap test and screening practices was carried out using pre-tested, interviewer administered, structured questionnaires. Participants in the intervention group received sessions of community based health information on cervical cancer screening tests while participants in the control group received health information on hypertension. Subsequently, participants in both groups were reassessed to evaluate the effect of the educational programme on the Pap test and cervical screening uptake. Data were analysed with the Epi-info version 6.04. Awareness about the Pap test was low at baseline; only $6.9 \%$ and $12.0 \%$ of participants in the intervention and control groups, respectively, had heard of Pap smears. Furthermore, less than $10 \%$ had correct information on the use of the Pap test. Post-intervention, there was a significant and proportional increase in the knowledge of the Pap test in the intervention group $(\mathrm{P}<0.05)$. However, uptake of the test was quite low in the intervention and control groups both pre- and post-intervention and there was no significant change in uptake. We concluded that essential schemes are required to enhance access to screening, as knowledge alone is insufficient to promote acceptance and use of cervical cytological screening tests.

\section{Introduction}

Cervical cancer is one of the most prevalent forms of carcinoma affecting women worldwide. ${ }^{1}$ It accounts for $12 \%$ of all cancers and global data have revealed an estimated 466,000 new cases of the disease annually. ${ }^{2,3}$ The agestandardised mortality rate of cervical cancer in developing countries is 9.6 per 100,000 women, which is twice the rate in developed countries. ${ }^{4}$ The disparity in prevalence between the developing and developed worlds can be attributed in part to lack of effective cytological screening programmes.

Cytological screening (the Papanicolaou smear or Pap smear) has been one of the most successful public health measures available for cancer prevention. ${ }^{5}$ Cervical cancer screening is widely available in developed countries and in most cases lesions are detected at the pre-cancer or early cancerous stage. ${ }^{6}$ Benefits of cervical cancer screening programmes in developed countries have been well documented. For instance, Denmark recorded a $25 \%$ decline in mortality following $40 \%$ coverage. $^{7}$ In Norway, a $5 \%$ coverage achieved a $10 \%$ fall in mortality. ${ }^{7}$ However, deaths from cervical cancer are still high in Nigeria and there is also a low level of awareness about cervical cancer and screening for cervical abnormalities. A Nigerian study by Ajayi and Adewole showed that only $3.5 \%$ of women attending a general outpatient clinic had heard about the Pap smear while only $1.2 \%$ had had the test prior to the study. ${ }^{8,9}$ The aim of our study was to provide information on the effectiveness of an educational programme on awareness and uptake of cervical cancer screening services (the Pap smear) by women in a model market in Lagos, Nigeria.

\section{Materials and Methods}

\section{Design}

Our study is part of an intervention (quasiexperimental) study conducted between April and July in 2006 to assess the effect of an educational programme on cervical awareness for market women in an urban area of Lagos, Nigeria. Details of this study can be found elsewhere. ${ }^{10}$

\section{Setting}

Our study was conducted in Lagos, the fourth most population-dense city in the world with 18,150 people per square kilometre ${ }^{11}$ and the largest commercial city in Nigeria. It was carried out in three phases. During the preintervention phase, baseline information on awareness of the Pap test and cervical cancer
Correspondence: Kikelomo Ololade Wright, Department of Community Health and Primary Health Care, Lagos State University College of Medicine, 1-5 Oba Akinjobi Street, GRA Lagos, Nigeria. Tel: +234.8023102545 .

E-mail: loladewright@yahoo.com

Key words: cervical cancer, screening, awareness, uptake, Pap smear.

Acknowledgements: the authors would like to acknowledge the contributions of Professor Adetokunbo 0. Lucas for his critical review throughout the entire work. Our appreciation also goes to the market women leaders and executive committees of both model markets.

Contributions: KOW contributed to the study concept and design, acquisition and interpretation of data; YAK, FAF participated in the data analysis and interpretation; BF participated in the study concept, interpretation of data, and revising of the intellectual content of the manuscript. All authors participated in the drafting, editing and approval of the final version of the manuscript.

Conflict of interest: the authors report no conflicts of interest.

Received for publication: 6 October 2010 . Accepted for publication: 20 January 2011.

This work is licensed under a Creative Commons Attribution 3.0 License (by-nc 3.0).

(C) Copyright K.O. Wright et al., 2011

Licensee PAGEPress, Italy

Journal of Public Health in Africa 2011; 2:e14

doi:10.4081/jphia.2011.e14

screening uptake was collected from participants (intervention and control groups) by trained interviewers using an interviewer administered questionnaire. During the intervention phase, health education was provided on cervical cancer screening tests with emphasis on the Pap smear, its benefit and procedure and on proximate health institutions that provide such services to the intervention group. In addition to counselling, culturally tailored and reader-friendly educational materials were designed, based on findings from the baseline survey in English and Yoruba (native) languages for the intervention group. A total of four meetings took place at the market, on Thursdays during the weekly environmental sanitation period when markets are shut to the public, with the assistance of the market leaders and executive committee. Similarly, the participants in the control group received health education on hypertension and had blood pressure measurements. A post-test was conducted three months post-intervention on both groups, using the same instrument, to provide sufficient time for a levelling effect. In 
order to reduce interviewer bias, research staff who administered the post-test assessment did not participate in the intervention phase.

\section{Sample size determination}

Sample size was determined based on a previous study on the Pap smear test in Nigeria. ${ }^{12}$ A minimum sample size of 78 was obtained for each group (intervention and control), an oversampling was done to allow for non-responses and attrition and a total of 350 participants (175 for each group) were enrolled.

\section{Participant recruitment}

Market women registered with the relevant local government authorities and who have lock-up shops (shops where goods are stored) were included in the study. A multi-stage sampling technique was used for recruiting the study participants. Two local government areas (LGAs) were selected randomly by balloting from a sampling frame of 10 LGAs with model markets - a model market being one which comprises appropriate social amenities. Subsequently, participants were recruited by the systematic random sampling method with a sampling interval of three calculated from the minimum number of lock-up shops in each market of 500 and a sample size of 175 in each market.

\section{Data analysis}

Epi-info 6.04 statistical software was used for data entry and analysis was done using Epiinfo 2002, Epi 6 and Microsoft Excel. Statistical tests of significance between pre- and postintervention data were done using Chi-square for categorical variables, with level of significance set at $\mathrm{P}<0.05$.

The Research and Ethical Committee of the Lagos University Teaching Hospital approved the study protocol. Permission was also sought from the necessary market authorities and informed consent obtained from the participants while confidentiality was assured.

\section{Results}

The majority of respondents in both groups were within the age range of 25-34 years, the mean ages being $34.9 \pm 12.7$ and $33.4 \pm 10.7$ for the intervention and control groups, respectively. Using the student's t-test for comparison of means, the computed t-value was 1.18 (less than a critical ratio of 2.021), which showed that the mean ages of both populations were similar. Furthermore, about two-thirds of the respondents were married. The majority of respondents in both groups had completed their secondary education. However, the intervention group had more women with no formal education than the control group. The difference between the two groups regarding age, marital status and educational levels was not statistically significant ( $\mathrm{P}>0.05)$ (Table 1). The demographic variables established comparability of both groups prior to intervention (educational programme).

\section{Knowledge about the Pap smear}

In the intervention group, the proportion of those who had heard of the Pap smear rose from $6.9 \%$ pre-intervention to $56.6 \%$ postintervention. The difference between both groups post-intervention was found to be statistically significant $(\mathrm{P}<0.01)$ (Table 2). At baseline, less than $10 \%$ of the participants in both groups knew that the Pap smear is a test for cervical abnormalities. After the intervention, a significant proportional increase was found in those in the intervention group who knew the indication for the Pap smear $(\mathrm{P}<0.05)$ (Table 3). Despite the fact that respondents who had completed their secondary education in the intervention group constituted the greatest proportion of those aware of the Pap smear test, there was no statistically

Table 1. Socio-demographic details of respondents.

\begin{tabular}{|c|c|c|c|}
\hline Variables & $\begin{array}{c}\text { Intervention } \\
(n=175) \\
\text { No. }(\%)\end{array}$ & $\begin{array}{l}\text { Control } \\
(n=175) \\
\text { No. }(\%)\end{array}$ & $\chi^{2}$ \\
\hline $\begin{array}{l}\text { Age-group (years) } \\
18-24 \\
25-34 \\
35-44 \\
45-54 \\
55-80 \\
\text { No response }\end{array}$ & $\begin{array}{c}30(17.1) \\
57(32.6) \\
39(22.3) \\
33(18.9) \\
12(6.9) \\
4(2.3)\end{array}$ & $\begin{array}{c}32(18.3) \\
73(41.7) \\
33(18.9) \\
27(15.4) \\
8(4.6) \\
2(1.1)\end{array}$ & $\begin{array}{l}\chi^{2}=4.60 \\
P=0.467\end{array}$ \\
\hline $\begin{array}{l}\text { Marital status } \\
\text { Single } \\
\text { Married } \\
\text { Separated } \\
\text { Divorced } \\
\text { Widowed }\end{array}$ & $\begin{array}{c}33(18.9) \\
126(72.0) \\
6(3.4) \\
0(0.0) \\
10(5.7)\end{array}$ & $\begin{array}{c}48(27.4) \\
115(65.7) \\
4(2.3) \\
2(1.1) \\
6(3.4)\end{array}$ & $\begin{array}{l}\chi^{2}=6.68 \\
P=0.154\end{array}$ \\
\hline $\begin{array}{l}\text { Educational background } \\
\text { No formal } \\
\text { Primary uncompleted } \\
\text { Primary completed } \\
\text { Secondary uncompleted } \\
\text { Secondary completed } \\
\text { Tertiary }\end{array}$ & $\begin{array}{c}22(12.6) \\
6(3.4) \\
28(16.0) \\
28(16.0) \\
70(40.0) \\
21(12.0)\end{array}$ & $\begin{array}{c}8(4.6) \\
10(5.7) \\
21(12.0) \\
30(17.1) \\
77(44.0) \\
29(16.6)\end{array}$ & $\begin{array}{c}\chi^{2}=10.22 \\
\mathrm{P}=0.069\end{array}$ \\
\hline
\end{tabular}

Table 2. Comparison of awareness of Pap smear (pre- and post-intervention) in both groups.

\begin{tabular}{lcccc} 
Heard of & \multicolumn{2}{c}{ Pre-intervention } & \multicolumn{2}{c}{ Post-intervention } \\
Pap smear & $\begin{array}{c}\text { Intervention } \\
(\mathrm{n}=175)\end{array}$ & $\begin{array}{c}\text { Control } \\
(\mathrm{n}=175)\end{array}$ & $\begin{array}{c}\text { Intervention } \\
(\mathrm{n}=175)\end{array}$ & $\begin{array}{c}\text { Control } \\
(\mathrm{n}=175)\end{array}$ \\
& No. $(\%)$ & No. $(\%)$ & No. $(\%)$ & No. $(\%)$ \\
Yes & $12(6.9)$ & $21(12.0)$ & $99(56.6)$ & $17(9.7)$ \\
No & $163(93.1)$ & $154(88.0)$ & $76(43.4)$ & $158(90.3)$ \\
\hline
\end{tabular}

$\chi^{2}=2.7, \mathrm{P}=0.100, \chi^{2}=86.70, \mathrm{P}<0.001$.

Table 3. Indication for Pap smear (pre- and post-intervention).

\begin{tabular}{lcccc}
\hline Indication for & \multicolumn{2}{c}{ Pre-intervention } & \multicolumn{2}{c}{ Post-intervention } \\
Pap smear & Intervention & Control & Intervention & Control \\
& $(n=175)$ & $(n=175)$ & $(n=175)$ & $(n=175)$ \\
& No. $(\%)$ & No. $(\%)$ & No. $(\%)$ & No. $(\%)$
\end{tabular}

Test for

\begin{tabular}{lcccc} 
Any cancer & $0(0.0)$ & $0(0.0)$ & $0(0.0)$ & $1(0.6)$ \\
CA breast & $4(2.3)$ & $0(0.0)$ & $5(2.9)$ & $0(0.0)$ \\
\hline CA cervix & $5(2.9)$ & $14(8.0)$ & $94(53.7)$ & $14(8.0)$ \\
Do not know & $3(1.7)$ & $7(4.0)$ & $0(0.0)$ & $2(1.1)$ \\
\hline No response & $163(93.1)$ & $154(88.0)$ & $76(43.4)$ & $158(90.3)$ \\
\hline
\end{tabular}

$\chi^{2}=10.12, \mathrm{DF}=3, \mathrm{P}=0.018, \chi^{2}=95.99, \mathrm{DF}=4, \mathrm{P}=0.000$. 
significant relationship between educational level and awareness of cervical cancer $(\mathrm{P}>0.05)$ (Table 4).

\section{Uptake of cervical screening}

Over $95 \%$ of respondents in both groups had never taken a Pap smear test. Despite the educational programme, there was no statistically significant difference between those who had had a Pap test before and after the intervention in either group ( $\mathrm{P}>0.05)$ (Table 5). Preintervention, the commonest reason in both samples for not doing a Pap smear was lack of awareness. The option others consisted of reasons such as no time, no interest, fear and not being promiscuous. Interestingly, there were statistically significant differences at baseline and post-intervention $(\mathrm{P}<0.05)$ (Table 6). Although the majority of respondents in both groups expressed willingness to have a Pap smear in the future at the pre-intervention phase, a higher proportional change of $19.5 \%$ was found in the intervention group post-intervention in contrast to a change of only $3.4 \%$ in the control group. This difference was statistically significant post-intervention $(\mathrm{P}<0.05)$ (Table 7).

\section{Discussion}

Regular cervical screening has been likened to an insurance put in place to avoid cataclysmic consequences. ${ }^{13}$ Our present study showed that less than $15 \%$ of respondents had heard about cervical screening using the Pap smear. Comparably, a Nigerian study on awareness of the prevention of cervical cancer among female health workers showed a paucity of knowledge among nurses and hospital maids, while $93.2 \%$ of all the female health workers who responded had never had a Pap smear done. ${ }^{14}$ In a similar Ghanaian study, as high as $93 \%$ of respondents had heard of cervical cancer and, even though $39 \%$ knew about Pap smears, only $8.5 \%$ had had a Pap test in the past. ${ }^{15}$

In our study, less than $5 \%$ of respondents had undergone a Pap smear test in the past, which corroborates the observation by Bishop et al. that only about $5 \%$ of women in developing countries are screened in a five-year period compared to $40-50 \%$ of women in the developed world. ${ }^{16}$ In Italy, as at 1998, 98.6\% of women had had at least one test within the past three years while by the year 2000 , in Belgium, $82.3 \%$ of women had had the opportunity to have one test. ${ }^{17}$ According to a survey, participation in cervical screening in Hong-Kong is about 59\% despite the availability of free or low-cost cytological screening programmes. ${ }^{18}$
It has been observed that availability and accessibility of cervical screening alone does not guarantee successful screening, as seen in a study done on Vietnamese immigrants in the United States, which revealed that most of the participants had never had Pap smears in spite of availability of facilities. ${ }^{17}$ This was owing to lack of knowledge. It was observed that as many as $75 \%$ of participants were ignorant of the use of Pap smears. ${ }^{17}$ This is similar to findings in our study in which less than $10 \%$ of respondents had correct information on the use of Pap smears (Table 3).

Despite the health education counselling in our study, uptake of the Pap test remained very low. This may be because of hesitancy in the adoption of innovations and behavioural modification by most individuals as well as cultural inhibitions. On the other hand, in a health intervention study among Asian women in Leicester using personal visits, videos and educational materials, an increased uptake of cervical cancer screening was reported. About $47 \%$ of women educated through video films

Table 4. Educational levels of the intervention group and awareness of Pap smear: heard of Pap smear.

\begin{tabular}{|c|c|c|c|c|}
\hline \multirow[t]{2}{*}{ Educational levels } & \multicolumn{2}{|c|}{ Pre-intervention } & \multicolumn{2}{|c|}{ Post-intervention } \\
\hline & $\begin{array}{c}\text { Yes } \\
\text { №. }(\%)\end{array}$ & $\begin{array}{l}\text { No } \\
\text { No. (\%) }\end{array}$ & $\begin{array}{l}\text { Yes } \\
\text { №. (\%) }\end{array}$ & $\begin{array}{c}\text { No } \\
\text { №. (\%) }\end{array}$ \\
\hline No formal & $0(0.0)$ & $22(13.5)$ & $15(15.2)$ & $16(21.1)$ \\
\hline Primary uncompleted & $0(0.0)$ & $6(3.7)$ & $4(4.0)$ & $2(2.6)$ \\
\hline Primary completed & $3(25.0)$ & $25(15.3)$ & 19(19.2) & $12(15.8)$ \\
\hline Secondary uncompleted & $1(8.3)$ & $27(16.6)$ & $3(3.0)$ & $3(3.9)$ \\
\hline Secondary completed & $5(41.7)$ & $65(39.9)$ & $47(47.5)$ & $38(50.0)$ \\
\hline Tertiary & $3(25.0)$ & $18(11.0)$ & 11(11.1) & $5(6.6)$ \\
\hline Total & $12(6.9)$ & 163(93.1) & $99(56.6)$ & $76(43.4)$ \\
\hline
\end{tabular}

$\chi^{2}=5.01, \mathrm{DF}=5 ; \mathrm{P}=0.414, \chi^{2}=2.50, \mathrm{DF}=5, \mathrm{P}=0.776$.

Table 5. Uptake of the Pap test in both groups (pre- and post-intervention).

\begin{tabular}{lcccc}
\hline Uptake of & \multicolumn{2}{c}{ Pre-intervention } & \multicolumn{2}{c}{ Post-intervention } \\
Pap test & $\begin{array}{c}\text { Intervention } \\
(\mathrm{n}=175)\end{array}$ & $\begin{array}{c}\text { Control } \\
(\mathrm{n}=175)\end{array}$ & $\begin{array}{c}\text { Intervention } \\
(\mathrm{n}=175)\end{array}$ & $\begin{array}{c}\text { Control } \\
(\mathrm{n}=175)\end{array}$ \\
& No. $(\%)$ & No. $(\%)$ & No. $(\%)$ & No. $(\%)$ \\
Yes & $2(1.1$ & $5(2.9)$ & $3(1.7)$ & $7(4.0)$ \\
No & $173(98.9)$ & $170(97.1)$ & $172(98.3)$ & $168(96.0)$ \\
\hline \multicolumn{2}{l}{ Yates $=0.58 ; \mathrm{P}=0.445 ;$ Yates $=0.93 ; \mathrm{P}=0.336}$. & & &
\end{tabular}

Table 6. Reasons for lack of uptake of the Pap test.

\begin{tabular}{|c|c|c|c|c|}
\hline \multirow{2}{*}{$\begin{array}{l}\text { Reasons for } \\
\text { non-uptake }\end{array}$} & \multicolumn{2}{|c|}{ Pre-intervention } & \multicolumn{2}{|c|}{ Post-intervention } \\
\hline & $\begin{array}{c}\text { Intervention } \\
(\mathrm{n}=175) \\
\text { No. }(\%)\end{array}$ & $\begin{array}{l}\text { Control } \\
(n=175) \\
\text { No. }(\%)\end{array}$ & $\begin{array}{c}\text { Intervention } \\
(\mathrm{n}=175) \\
\text { No. }(\%)\end{array}$ & $\begin{array}{l}\text { Control } \\
(n=175) \\
\text { No. }(\%)\end{array}$ \\
\hline Do not know where to go & $1(0.6)$ & $0(0.0)$ & $1(0.6)$ & $0(0.0)$ \\
\hline Cost & $1(0.6)$ & $0(0.0)$ & $6(3.4)$ & $0(0.0)$ \\
\hline Not at risk & $8(4.6)$ & $1(0.6)$ & $9(5.1)$ & $5(2.9)$ \\
\hline No symptoms & $35(20.0)$ & $3(1.7)$ & $88(50.3)$ & $15(2.9)$ \\
\hline Not aware & $123(70.3)$ & $154(88.0)$ & $61(34.9)$ & $151(86.3)$ \\
\hline Others & $1(0.6)$ & $1(0.6)$ & $27(15.4)$ & $0(0.0)$ \\
\hline
\end{tabular}

$\chi^{2}=37.59, \mathrm{DF}=5, \mathrm{P}=0.0001 ; \chi^{2}=124.29, \mathrm{DF}=5, \mathrm{P}=0.000$.

Table 7. Willingness to have a Pap smear in future.

\begin{tabular}{lcccc}
\hline Willing & \multicolumn{2}{c}{ Pre-intervention } & \multicolumn{2}{c}{ Post-intervention } \\
& $\begin{array}{c}\text { Intervention } \\
(\mathrm{n}=175)\end{array}$ & $\begin{array}{c}\text { Control } \\
(\mathrm{n}=175)\end{array}$ & $\begin{array}{c}\text { Intervention } \\
(\mathrm{n}=175)\end{array}$ & $\begin{array}{c}\text { Control } \\
(\mathrm{n}=175)\end{array}$ \\
& No. $(\%)$ & No. $(\%)$ & No. $(\%)$ & No. $(\%)$ \\
Yes & $111(63.4)$ & $166(94.9)$ & $145(82.9)$ & $172(98.3)$ \\
No & $58(33.1)$ & $5(3.2)$ & $28(16.0)$ & $3(1.7)$ \\
\hline Do not know & $6(3.4)$ & $4(2.3)$ & $2(1.1)$ & $0(0.0)$ \\
\hline
\end{tabular}

$\chi^{2}=2.99, \mathrm{DF}=2, \mathrm{P}=0.224, \chi^{2}=9.94, \mathrm{DF}=2, \mathrm{P}=0.007$. 
and face-to-face meetings underwent Pap smears compared to $37 \%$ of those educated by personal visits and flash cards. ${ }^{19}$

In a quasi-experimental study conducted in Houston, Texas, it was hypothesised that cancer screening promotional programmes increased screening rates. ${ }^{20}$ At the baseline population survey of that study, a small but significant proportion of women (10-15\%) had not had Pap smear tests previously. However, a follow-up showed an upward trend toward greater uptake among the younger women. ${ }^{20}$ In the United States and United Kingdom, women's uptake of cervical screening has been related to intrinsic factors such as knowledge, attitude and beliefs. ${ }^{21,22}$

There are several reasons that militate against the participation of women in cervical screening programmes. Some of these include lack of awareness of test indications and benefits, inconvenient clinic hours, lack of female screeners, administrative failures, fear of embarrassment, fear of pain or detection of cancer and considering oneself not at risk of developing cervical cancer. ${ }^{21,23-24}$ Other deterrents include the perception that cancer is an inevitably fatal disease, opposition by male sexual partners, rejection of pelvic examination and perceived high cost. ${ }^{25}$

In our study, reasons for lack of uptake that featured post-intervention among the intervention group include lack of symptoms, not being at risk and cost (Table 6). Similarly, uptake was found to be low among female nurses in Nnewi, Nigeria as only $5.7 \%$ of them had ever undergone a Pap smear despite a high awareness of screening services (87\%). While $37.1 \%$ of them had no reason for not screening, $15 \%$ were afraid of the possible outcome and $25 \%$ felt they were not likely candidates for cancer of the cervix. ${ }^{26}$

It is encouraging to note that over $60 \%$ of respondents in both the intervention and the control groups of our study expressed willingness to undergo Pap testing both pre- and postintervention (Table 7). In a South Eastern Minnesota study on cancer screening behaviours and attitudes of women aged 18 years and older, over $90 \%$ of respondents expressed a desire to have Pap smears if physicians would enlighten them on its importance. ${ }^{27}$

It is clear from our study that awareness of the Pap test does not necessarily lead to its immediate uptake, although it may be presumptuous to expect significant changes in practice within an interval of three months. Our respondents are inclined to participate in screening programmes at a future date if issues of cost are taken care of and safety guaranteed. Interestingly, the baseline survey showed $94.9 \%$ of the controls as more willing compared to $63.4 \%$ of the experimental group.

\section{Study limitations}

The findings have limited generalisability as the study was restricted to only two model markets in Lagos. In addition, the inability to provide free or subsidised screening as a result of scarce resources was another limitation of the study.

\section{Conclusions}

The effect of an educational programme on market women was apparent in knowledge change; however, an immediate effect was not evident in the practices of the sampled population, which had not changed within an interval of three months. Some reasons proffered by participants for non-uptake of the Pap smear test include cost, lack of time and perceptions of not being at risk even though the majority was better informed about the Pap smear, its use and those who require testing. It is evident that pivotal intervention strategies are required, which must be hinged on cultural factors, overcoming economic and physical barriers as well as enhancing access to screening, as knowledge alone is insufficient to promote acceptance of Pap smear testing.

\section{References}

1. Parkin DM, Pisani P, Ferlay J. Estimates of worldwide frequency of eighteen major cancers in 1985. Int J Cancer 1993,54:594606.

2. World Health Organization. Cervical cancer screening in developing countries: Report of a WHO Consultation. WHO, 2002.

3. Program for Appropriate Technology in Health (PATH): Planning appropriate cervical cancer prevention programs. 2nd ed., 2000.

4. Pisani P, Parkin DM, Bray F, Ferlay J. Estimates of the worldwide mortality from 25 cancers in 1990. Int $\mathrm{J}$ Cancer 1999;24: 83:18-29.

5. Alliance for Cervical Cancer Prevention. The case for investing in cervical cancer prevention. Cervical Cancer Prevention Issues in Depth, Seattle: ACCP, No. 3, 2004.

6. Marcus AC, Crane LA. A review of cervical cancer screening intervention research: implications for public health programs and future research. Prev Med 1998;27:1331.

7. Shanta V. Perspectives in cervical cancer prevention in India. The International Network for Cancer Treatment and Research, 2005.

8. Ajayi I0, Adewole IF. Determinants of util- isation of cervical cancer screening facility in a low socio-economic setting in Nigeria. J Obstet Gynaecol 1998;18:154-8.

9. Ajayi IO, Adewole IF. Knowledge and attitude of general outpatient attendants in Nigeria to cervical cancer. Cent Afr J Med 1998;44:41-3.

10. Wright K0, Kuyinu YA, Faduyile FA. Community education on cervical cancer amongst market women in an urban area of Lagos, Nigeria. Asian Pac J Cancer Prev 2010;10:137-40.

11 City Mayors: Largest cities in the world ranked by population density. Address: http://www.citymayors.com/statistics/large st-cities-density-125.html Accessed 0ct 1, 2010).

12. Ogunbode 00, Ayinde OA. Awareness of cervical cancer and screening in a Nigerian female market population. Ann Afr Med 2005;4:160-3.

13. Sasiene PD. Outcomes of screening to prevent cancer: thinking of screening as insurance. BMJ 2003;327:50.

14. Ayinde OA, Omigbodun AO. Knowledge, attitudes and practices related to prevention of cancer of the cervix among female health workers in Ibadan. J Obstet Gynaecol 2003;23:59-62.

15. Adanu RMK. Cervical cancer knowledge and screening in Accra, Ghana. J Womens Health and Gend Based Med 2002;11:4878.

16. Bishop A, Wells E, Sherris J. Cervical cancer: evolving prevention strategies for developing countries. Reproductive Health Matters (RHM). 1995;6:60-71.

17. Kritpetcharat 0, Suwanrungruang $K$, Sriamporn $\mathrm{S}$, et al. The coverage of cervical cancer screening in Khon Kaen, Northeast Thailand. Asian Pac J of Cancer Prev 2003;4:103-5.

18. Family Planning Association of Hong Kong. Knowledge, attitude and practice of family planning survey in Hong Kong 1997. Hong Kong: Family Planning Association of Hong Kong, 1999.

19. Kelly AW, Wollan PC, Trapp MA. A program to increase breast and cervical cancer screening for Cambodian women in a Midwestern community. Mayo Clin Proc 1996;72:437-44.

20. McAlister AL, Fernandez-Esquer ME, Ramirez Ag, et al. Community level cancer control in a Texas barrio: Part II-Baseline and preliminary outcome findings. J Natl Cancer Inst Monogr 1995;18:123-6.

21. Fylan F. Screening for cervical cancer: a review of women's attitudes, knowledge and behaviour. Br J Gen Pract 1998;48: 1509-14.

22. Kim K, Yu ESH, Chen EH, et al. Cervical cancer screening knowledge and practices amongst Korean-American women. 
Cancer Nurs 1999;22:297-302.

23. Summers A, Fillard B. Improving the coverage and quality of cervical screening: women's views. J Public Health Med 1995; 17:277-81.

24. Najem GR, Batuman F, Smith AM. Papanicolaou test status among inner city adolescent girls. Am J Prev Med 1996;12: 482-6.

25. Lazcano-Ponce EC. Barriers to early detection of cervical-uterine cancer in Mexico. J Women's Health 1999;8:399-408.

26. Udigwe G0. Knowledge, attitude and practice of cervical cancer screening (Pap smear) among female nurses in Nnewi, South Eastern Nigeria. Niger J Clin Pract 2006;9:40-3.

27. Kottke TE, Trapp MA, Fores MM, et al. Cancer screening behaviors and attitudes of women in Southeastern Minnesota. JAMA 1995;273:1099-105. 